\title{
Identidade Própria
}

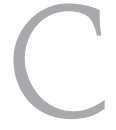

omo editores da Revista Brasileira de Reumatologia (RBR), é com muita satisfação que contemplamos o rumo que vem cada vez mais se firmando neste órgão oficial de comunicação científica. Uma das principais funções de um jornal científico nacional é legitimar e dar identidade ao trabalho de interesse regional, difundindo assuntos locais, que, além do valor informativo, podem potencialmente resultar no despertar das políticas de saúde e influenciar diretamente a tomada de decisões na melhoria da distribuição de recursos financeiros pelos órgãos competentes.

A qualidade de um jornal como o nosso reflete a excelência da ciência praticada por nossa comunidade. Todo cientista deseja ter seu trabalho reconhecido e o reconhecimento somente ocorre após o mesmo ter sido publicado.

$\mathrm{O}$ artigo de Medeiros e cols.(1), patrocinado pela Sociedade Brasileira de Reumatologia (SBR), relata o resultado de pesquisa nacional sobre as condutas usuais entre os reumatologistas brasileiros, no qual ficou patente uma homogeneidade de conduta na abordagem das principais afecções reumatológicas. Interessantemente, a devolução dos questionários refletiu o que temos observado em relação à participação e colaboração no envio de artigos científicos para publicação em nossa revista, na qual temos contado com a ínfima colaboração de colegas da região centro-oeste. - Alô Mato Grosso, Mato Grosso do Sul, Goiás e Distrito Federal!

No artigo dos colegas Souza e cols. ${ }^{(2)}$ divulga-se o atendimento de reumatologia no município de São Paulo, demonstrando a deficiente distribuição do especialista, o qual encontra-se concentrado nas universidades,

\section{REFERÊNCIAS}

1. Medeiros MMC, Ferraz MB, Vilar MJP, Santiago MB e cols. Condutas usuais entre os reumatologistas brasileiros: levantamento nacional. Rev Bras Reumatol 46: 82-92, 2006.

2. Souza DCC, Minto CM, Ciconelli RM. Atendimento em reumatologia no município de São Paulo: Análise na gestão plena do Sistema Único de Saúde (SUS) - Ano 2004. Rev Bras Reumatol 46: 93-102, 2006.

3. Abreu MMA, Kowlasi SC, Ciconelli Rm, Ferraz MB. Avaliação do perfil sociodemográfico, clínico-laboratorial e terapêutico dos pacientes com artrite reumatóide que participaram de projetos de pesquisa na Escola Paulista de Medicina, nos últimos 25 anos. Rev Bras Reumatol 46: 103-109, 2006.

4. Lopes RF, Farias MLF. Aspectos genéticos, influência do eixo e muito pouco a cargo das unidades básicas de saúde. Embora a análise de tais dados seja restrita ao município de São Paulo, sem dúvida pode servir de alerta às autoridades responsáveis pela potencial dificuldade de acesso ao especialista em afecções tão comuns e universalmente distribuídas.

O artigo enviado por Abreu e cols.(3) documenta radical mudança no perfil e desenvolvimento da pesquisa científica em nosso meio, acompanhando a tendência mundial. Os temas abordados há 25 anos concentravamse em estudos sorológicos e, nos últimos anos, nota-se uma maior diversidade na abordagem de temas, assim como uma maior preocupação com a qualidade de vida.

Nesta edição, somos ainda brindados com três excelentes artigos de revisão ${ }^{(4,5,6)}$ que abordam aspectos atuais da osteoporose e o uso de agentes biológicos inibidores de TNF na artrite reumatóide juvenil, e o abrangente artigo sobre as manifestações otorrinolaringológicas nas doenças reumáticas auto-imunes.

E, como sempre, contamos com a inestimável colaboração de Boris $\mathrm{Cruz}^{(7)}$ com atualização em epidemiologia, e, como não poderia deixar de ser, a útil e prática seção dos colegas Artur da Rocha Correa Fernandes e Jamil Natour ${ }^{(8)}$ com avaliação das costelas através da imagem.

Agradecemos a todos os colaboradores da RBR que têm tornado a leitura de nosso meio de comunicação científica uma referência para a informação e atualização da nossa especialidade.

Laís V. Lage e Roger A. Levy Editores Científicos da RBR

GH/IGFl e novas possibilidades terapêuticas na osteoporose idiopática - artigo de revisão. Rev Bras Reumatol 46: 110-117, 2006.

5. Pereira DB, Amaral JLA, Szajubok JCM e cols. Manifestações otorrinolaringológicas nas doenças reumáticas auto-imunes. Rev Bras Reumatol 46: 118-125, 2006.

6. Martins P, Medeiros AC, Goldeinstein-Schainberg C. O papel dos inibidores de fator de necrose tumoral no tratamento da artrite idiopática juvenil. Rev Bras Reumatol 46: 126-133, 2006.

7. Cruz, BA. Atualização em Reumatologia: Epidemiologia. Rev Bras Reumatol 46: 141-146, 2006.

8. Narahashi E, Yamada AF, Hernandez Filho G e cols. Avaliação das costelas através da imagem. Rev. Bras Reumatol 46: 137$140,2006$. 